\title{
Pattern of Metastasis in Cervical Lymph Nodes and Topographic Distribution of Primary Site: Study of 375 Cases
}

\author{
Jetly D. ${ }^{1}$, Thummar . $^{2}$ \\ ${ }^{1}$ Dr. Dhaval Jetly, Associate Professor and Head, ${ }^{2}$ Dr. Siddharth Thummar, Resident Doctor; Both Authors are Attached \\ with Pathology Department, Gujarat Cancer and Research Institute, Ahmedabad, India.
}

Corresponding Author: Dr. Siddharth Thummar, Resident Doctor, Pathology Department, Gujarat Cancer and Research Institute, Ahmedabad, India. E-mail: siddharthkpatel@yahoo.co.in

\begin{abstract}
Introduction: Lymph nodes are the most common site of metastatic malignancy and presence of metastatic tumor in lymph nodes is essential for the management and prognosis of cancer. Cervical lymph node metastasis most commonly develop from oral cavity malignancies. Tumors of Upper Aerodigestive tract, Salivary and Thyroid glands and any other sites of the body can present as cervical nodal metastasis. The topographic correlations are helpful clues to the most common sites of origin of metastases in cervical lymph nodes. Objectives: (1) Typing of Metastatic Tumor, its Prevalence and Demographic Incidence in cervical lymph nodes. (2) Distribution of Cervical lymph node metastasis \& Relevance to probable Primary Site. Methodology: In the study, FNAC and/or Biopsy were taken from enlarged cervical lymph nodes to confirm the metastatic tumor and to type the tumor. IHC was done whenever necessary for diagnosis and to confirm the primary site. Relevant clinical details and patient history were collected from patients' case file and electronic patients' records. Total 375 malignant metastatic cases were included in the study for analysis. Conclusion: SCC from head and neck region is the most common metastatic malignancy present in the cervical lymph nodes. SCC from Lung, Esophagus or Cervix can also present as metastatic lymph node. Adenocarcinoma and Neuroendocrine carcinoma from Lung or GI Tract in Males \& Ductal Carcinoma of Breast and Papillary Thyroid Carcinoma in Females can also involve Neck Lymph nodes.
\end{abstract}

Key words: Cervical Lymph node, Metastasis, Primary site, SCC

\section{Introduction}

Lymph nodes are the most common site of metastatic malignancy and sometimes constitute the first clinical manifestation of the disease. The task of the pathologist is to identify the presence of a malignant process in the node, to establish whether it is metastatic or not, andif, metastaticto provide an estimate of its amount, microscopic type, and possible source. Establishing the presence of metastatic tumor in lymph nodes is essential for the management and prognosis of cancer. In solid tumors, lymph node status is the most important indicator of clinical outcome [1].

Cervical lymph node metastasis most commonly but, not always develop from oral cavity malignancies. Apart from oral malignancies, squamous cell carcinoma of the upper Aerodigestive tract, Salivary gland malignancies, Thyroid cancers and skin cancers of head and neck region can present as cervical nodal

Manuscript received: $10^{\text {th }}$ February 2019

Reviewed: $20^{\text {th }}$ February 2019

Author Corrected: $28^{\text {th }}$ February 2019

Accepted for Publication: $5^{\text {th }}$ March 2019 metastasis. Cervical lymph nodes, particularly upper jugular and posterior cervical nodes, drain the head and neck and may harbour metastatic carcinomas originating in the Nasopharynx, Tonsillar fossa, Tongue, Floor of the mouth, Thyroid, Extrinsic larynx, Facial skin, and Scalp. Scalene lymph nodes representing the lower, deep jugular chain are commonly the site of metastases from Intrathoracic carcinomas, particularly in the Lungs. The supraclavicular lymph nodes are most often the site of metastases of Intra abdominal cancers.

The left supraclavicular lymph node, frequently invaded by Gastric carcinoma and less commonly other Gastro intestinal tract carcinoma, is classically known as the Virchow node. The topographic correlations are helpful clues to the most common sites of origin of metastases in various groups of regional lymph nodes [2].

Besides all this, Infraclavicular malignancies can also present as neck node metastasis. 
Not infrequently, a lymph node metastasis is discovered before an occult primary tumor is detected. In such cases, to identify the Unknown primary tumor, extensive studies of the lymph node metastases, including immunohistochemistry in addition to detailed histopathology, are often necessary. It is estimated that 5 to $7 \%$ of cancer patients present with a metastatic tumor of unknown origin [3,4]. Carcinomas of the Nasopharynx and Oropharynx are notorious for presenting with metastases in the cervical lymph nodes while the primary neoplasm remains unnoticeable [5].

Sometimes tumors like base of tongue or hypopharynx with local spread may present as nodal mass in neck and finding of primary site is difficult clinically or radiologically. Not uncommonly, the histologic pattern and cell morphology characteristic of a tumor are no longer recognizable in its metastases. Identifying the primary tumor may be difficult, often frustrating, yet indispensable for treatment. All available methods of cytopathology, histopathology and immunohistochemistry along with thorough clinico-radiological evaluation are required for typing and subtyping of metastatic tumor.

\section{Aims of This Study are}

1) Typing of Metastatic Tumor and its Prevalence in Cervical Lymph Nodes.

2) Demographic Incidence of Metastatic Cervical Lymph Nodes.

3) Distribution of Cervical Lymph Node Metastasis \& Relevance to probable Primary Site.

\section{Material and methods}

Type of study: Prospective study

Sample Collection and Methods:The present study was conducted on patients present with cervical lymph

\section{Original Research Article}

node enlargement during the period of one year. In the study, FNAC and/or Biopsy were taken from enlarged cervical lymph nodes to confirm the metastatic tumor and to type the tumor. For the further typing of tumor, Immunohistochemistry was done whenever necessary.

Inclusion Criteria: All $(\mathrm{n}=375)$ malignant metastatic cases of cervical lymph nodes were included in the study. Patients with known and unknown primary tumor site were included.

Exclusion Criteria: Patients with primary neoplasm of lymph node e.g. malignant lymphoma and Post-surgery specimens of modified neck dissection in which lymph nodes are positive for metastatic tumor were excluded.

Analysis: Out of total 375 cases, FNAC was done on 137 cases and both FNAC and Biopsy were done on 36 cases. Rest of the cases were confirmed by Biopsy. IHC was performed in 70 cases out of total 375 cases which could not be classified on histopathology or primary sites of tumor was not known.

Relevant clinical details and patient history were collected from patients' case file and electronic patients' records. To determine primary site in cases of unknown primary, radiological details were noted and Immunohistochemistry (IHC) was performed on tissue blocks.

All cytological, histological and/or Immunohistochemical findings were noted and reviewed for morphological diagnosis.

Statistical Methods: Statistical analysis was performed on collected data using standard statistical software (SPSS).

Ethical Considerations: No Ethical Issue related to the study.

\section{Result}

In the Present Study, A Total of 375 consecutive Cases having Metastatic Cervical Lymphadenopathy were Included for Analysis.

Table-1: Demographic distribution of Metastatic Cervical Lymphadenopathy.

\begin{tabular}{|c|c|c|}
\hline Age Group & Frequency & Percentage \\
\hline $0-20$ & 8 & $2.13 \%$ \\
\hline $21-40$ & 41 & $10.93 \%$ \\
\hline $\mathbf{4 1 - 6 0}$ & $\mathbf{2 0 0}$ & $\mathbf{5 3 . 3 3 \%}$ \\
\hline $61-80$ & 121 & $32.27 \%$ \\
\hline $81-100$ & 5 & $1.33 \%$ \\
\hline Total & $\mathbf{3 7 5}$ & $\mathbf{1 0 0 . 0 0 \%}$ \\
\hline Sex & Males- $\mathbf{2 9 8}(\mathbf{7 9 . 4 7 \% )}$ & Females- $\mathbf{7 7}(\mathbf{2 0 . 5 3 \% )}$ \\
\hline
\end{tabular}


Table-2: Metastatic Pattern in Malignant Cervical Lymph Nodes.

\section{Original Research Article}

\begin{tabular}{|c|c|c|}
\hline Metastatic tumor & Frequency & Percentage \\
\hline Adenocarcinoma & 28 & $7.47 \%$ \\
\hline Anaplastic carcinoma thyroid & 2 & $0.53 \%$ \\
\hline Ductal carcinoma breast & 24 & $6.40 \%$ \\
\hline Germ cell tumor & 2 & $0.53 \%$ \\
\hline Granulocytic sarcoma & 3 & $0.80 \%$ \\
\hline Nasopharyngeal carcinoma & 4 & $1.06 \%$ \\
\hline Neuroendocrine carcinoma & 20 & $5.33 \%$ \\
\hline Papillary thyroid carcinoma & 9 & $2.40 \%$ \\
\hline Poorly diffentiated carcinoma & 11 & $2.93 \%$ \\
\hline Squamous cell carcinoma & 262 & $69.87 \%$ \\
\hline Others* & 10 & $2.66 \%$ \\
\hline Total & $\mathbf{3 7 5}$ & $\mathbf{1 0 0 . 0 0 \%}$ \\
\hline
\end{tabular}

*Others include Epithelioid Sarcoma, High grade Serous Carcinoma Ovary, Medullary Carcinoma Thyroid, Medulloblastoma, Malignant Melanoma, PNET, RCC, Sarcomatoid Carcinoma, Spindle cell Sarcoma

Table-3: Distribution of Metastatic Tumors in Females.

\begin{tabular}{|c|c|c|}
\hline Metastatic tumor & Frequency & Percentage \\
\hline Adenocarcinoma & 5 & $6.49 \%$ \\
\hline Anaplastic carcinoma thyroid & 2 & $2.60 \%$ \\
\hline Ductal carcinoma breast & 24 & $31.17 \%$ \\
\hline Granulocytic sarcoma & 2 & $2.60 \%$ \\
\hline Neuroendocrine carcinoma & 2 & $2.60 \%$ \\
\hline Papillary thyroid carcinoma & 7 & $9.09 \%$ \\
\hline Squamous cell carcinoma & 31 & $40.26 \%$ \\
\hline Others* & 4 & $5.19 \%$ \\
\hline Total & $\mathbf{7 7}$ & $\mathbf{1 0 0 . 0 0 \%}$ \\
\hline
\end{tabular}

*Others include High grade Serous Carcinoma Ovary, PDCA, PNET, Nasopharyngeal Undifferentiated Carcinoma

Table-4: Distribution of Metastatic Tumors in Males.

\begin{tabular}{|c|c|c|}
\hline Metastatic tumor & Frequency & Percentage \\
\hline Adenocarcinoma & 23 & $7.72 \%$ \\
\hline Germ cell tumor & 2 & $0.67 \%$ \\
\hline Nasopharyngeal carcinoma & 3 & $1.00 \%$ \\
\hline Neuroendocrine carcinoma & 18 & $6.04 \%$ \\
\hline Papillary thyroid carcinoma & 2 & $0.67 \%$ \\
\hline Poorly differntiated carcinoma & 10 & $3.36 \%$ \\
\hline Squamous cell carcinoma & 231 & $77.52 \%$ \\
\hline Others* & 9 & $3.02 \%$ \\
\hline Total & $\mathbf{2 9 8}$ & $\mathbf{1 0 0 . 0 0 \%}$ \\
\hline
\end{tabular}

*others include epithelioid sarcoma, granulocytic sarcoma, medullary carcinoma thyroid, medulloblastoma, malignant melanoma, PNET, RCC, sarcomatoid carcinoma, spindle cell sarcoma. 
Table-5: Distribution of Primary Site in Metastatic SCC.

\section{Original Research Article}

\begin{tabular}{|c|c|c|}
\hline Primary site & Frequency & percentage \\
\hline Alveolus & 3 & $1.15 \%$ \\
\hline Angle of mouth/lip & 2 & $0.76 \%$ \\
\hline Buccal mucosa & 37 & $14.12 \%$ \\
\hline Base of tongue & 34 & $12.98 \%$ \\
\hline Cervix & 4 & $1.53 \%$ \\
\hline Esophagus & 10 & $3.82 \%$ \\
\hline Eyelid & 1 & $0.38 \%$ \\
\hline Larynx & 54 & $20.61 \%$ \\
\hline Lung & 14 & $5.34 \%$ \\
\hline Maxilla & 4 & $1.53 \%$ \\
\hline Nasopharynx & 8 & $3.05 \%$ \\
\hline Oropharynx & 7 & $2.67 \%$ \\
\hline Palate & 5 & $1.91 \%$ \\
\hline Scalp ulcer & 1 & $0.38 \%$ \\
\hline Tongue & 19 & $7.25 \%$ \\
\hline Tonsil & 14 & $5.34 \%$ \\
\hline Unknown & 23 & $8.78 \%$ \\
\hline Vallecula & 22 & $8.40 \%$ \\
\hline Total & $\mathbf{2 6 2}$ & $\mathbf{1 0 0 . 0 0 \%}$ \\
\hline
\end{tabular}

Table-6: Distribution of Primary Site in Metastatic Adenocarcinoma.

\begin{tabular}{|c|c|c|}
\hline Primary site & Frequency & Percentage \\
\hline Esophagus & 4 & $14.29 \%$ \\
\hline Gall bladder & 1 & $3.57 \%$ \\
\hline Lung & 15 & $53.57 \%$ \\
\hline Ovary & 3 & $10.71 \%$ \\
\hline Rectum & 2 & $7.14 \%$ \\
\hline Stomach & 3 & $10.71 \%$ \\
\hline Total & $\mathbf{2 8}$ & $\mathbf{1 0 0 . 0 0 \%}$ \\
\hline
\end{tabular}

Table-7: Distribution of Primary Site in Metastatic Neuroendocrine Carcinoma.

\begin{tabular}{|c|c|c|}
\hline Primary site & Frequency & Percentage \\
\hline Esophagus & 1 & $5.00 \%$ \\
\hline Lung & 16 & $80.00 \%$ \\
\hline Mediastinal mass & 1 & $5.00 \%$ \\
\hline Pancreas & 1 & $5.00 \%$ \\
\hline Thymus & 1 & $5.00 \%$ \\
\hline Total & $\mathbf{2 0}$ & $\mathbf{1 0 0 . 0 0} \%$ \\
\hline
\end{tabular}

\section{Discussion}

In the present study, we analysed 375 cases of metastatic cervical lymph nodes confirmed by FNAC and/or Biopsy.

Majority of the cases were of age group 41-60 years i.e. $53 \%$ cases followed by age group $61-80$ years i.e. $32 \%$ cases(Table-1). Age ranges were almost comparable to the study done by Naresh et al[6], in which most common age group was also 41-60 years i.e. 54\% followed by $61-80$ years i.e. $25 \%$. Males were most frequently involved in present study i.e. $80 \%$. (Table-1) Most common secondary malignancy found in cervical lymph node was squamous cell carcinoma i.e. $70 \%$ of total metastatic tumors (Table-2) But in males, the percentage was higher i.e. $78 \%$ and in females, it was only $40 \%$. After squamous cell carcinoma, most 
common malignant metastatic tumor found was adenocarcinoma of lung i.e. $7 \%$ in males. In females, most common malignant metastatic tumor found in cervical lymph nodes after squamous cell carcinoma was ductal carcinoma breast i.e. $31 \%$ followed by papillary carcinoma of thyroid i.e. $10 \%$ (Table 3,4$)$

Out of total $70 \%$ cases of metastatic SCC, most common primary site was oral cavity i.e. $25 \%$, followed by pharynx i.e. $24 \%$ and larynx i.e. $21 \%$ cases.

Lung and esophagus squamous cell carcinoma are not uncommon. Rare primary sites were eyelid, scalp, maxilla and cervix. (Table-5) In study by Candela et al[7], metastases were frequent in oral cavity tumors, with a mean prevalence of $30.1 \%$. The corresponding figure for oropharyngeal cancer was $10.3 \%$, largely because of the high prevalence in $\mathrm{N}+$ disease [7].

Out of total $8 \%$ cases of metastatic adenocarcinoma i.e. 28 cases, most common primary site found was lung in $54 \%$ cases followed by esophagus and ovary i.e. $15 \%$ and $11 \%$ respectively. (Table-6) A study of 58 cases of remote metastasis in cervical lymph nodes done by Wagh $A[8]$ also found $41 \%$ cases of lung metastasis in supraclavicular lymph nodes that is comparable to present study. Davis et al [9] reported the frequency of cervical lymph node involvement in patients with lung cancer, to vary from $1.5 \%$ to $32 \%$.

Out of total $5.3 \%$ cases of neuroendocrine carcinoma i.e. 20 cases, most common primary site found was lung in $80 \%$ cases. Other rare sites were esophagus, mediastinal mass, thymus and pancreas i.e. 1 case each (Table-7) Metastatic ductal carcinoma of breast was found in total $6.4 \%$ of cases and in females, it was present in nearly $30 \%$ of cases.

Although the occurrence of neck metastases in breast carcinoma is low $(2.3 \%$ to $4.3 \%)[10-13]$, breast cancer is the most common distant primary to metastasize to neck lymph nodes. ${ }^{12}$ The cervical nodes most often affected are the supra-clavicular lymph nodes; jugular chain metastases are an extraordinarily rare event $(\leq 0.5 \%$ of cases) $[14]$.

Metastatic papillary carcinoma of thyroid was found in total $2.4 \%$ of cases and in females, it was present in $9 \%$ cases. (Table-2,3)El-Foll HA[15] has done study of 44 cases diagnosed with papillary carcinoma of thyroid and found nearly $40 \%$ cases with neck lymph node metastasis. In view of this and present study, papillary carcinoma and other malignancy of thyroid are to be considered in differential diagnosis in metastatic cervical lymph nodes especially in females.

\section{Original Research Article}

In any malignancy, presence or absence of lymph node metastasis is the most significant prognostic factor in view of management and survival [1]. Cervical lymph nodes are group of nearly 300 smalls to medium sized lymph nodes present on either side of neck [16]. They are classified into numeric levels i.e. level I to VI according to anatomic location of lymph nodes [17].

Cervical lymph nodes drain the head and neck region and harbour metastasis from regional head and neck SCC i.e. from oral cavity, pharynx, larynx or facial skin. Left supraclavicular or Virchow's lymph nodes are connected to the thoracic duct and are involved in various tumors located distant to the neck region or tumors located infraclavicular compartment [17].

Wide range of the pattern of metastasis to the neck lymph nodes are present. Tumors with known primary sites of oral cavity and upper aero digestive tracts i.e. pharynx, larynx are the most common metastatic malignancies found in the neck lymph nodes [18]. Tumors with known primary site other than oral cavity or upper aero digestive tract i.e. breast, lung, gastrointestinal tract, thyroid, urogenital tract, central nervous system, various sarcomas or haematolymphoid malignancies are found not uncommonly in metastatic neck lymph nodes [2]. Patients with unknown primary site of tumors are also present commonly with cervical lymph node metastasis.

Most frequent secondary malignancies in cervical lymph nodes in which primary sites remain unknown are squamous cell carcinoma metastasise from nasopharynx, oropharynx and hypopharynx [19]. In metastatic adenocarcinoma to cervical lymph nodes, most common primary site is to be the lung in males and breast ductal carcinoma in females [11]. Sometimes patients present with occult metastasis in cervical lymph nodes, in which primary site is not found even after vigorous search by means of imaging or blind biopsy techniques [20]. Other type of patients with cervical lymph node metastasis are that they present months or years after successful surgery, chemotherapy or radiotherapy i.e. recurrence/relapse after cure.

\section{Conclusion}

SCC is the most common metastatic malignancy present in the cervical lymph nodes. SCC spreads from regional Head and Neck primary sites most commonly but not always. SCC from Lung, Esophagus or Cervix can also present as metastatic lymph node in Head and Neck and should be considered as differential diagnosis when primary tumor site not known. In patients younger than 20 years of age, malignancy other than SCC should 


\section{Original Research Article}

always keep in differential diagnosis like Nasopharyngeal Carcinoma or Haematolymphoid Malignancy. Not uncommonly, other secondary malignancies like Adenocarcinoma and Neuroendocrine carcinoma from Lung or GI Tract in Males \& Ductal Carcinoma of Breast and Papillary Thyroid Carcinoma in Females can also involve Neck Lymph nodes. Regional metastasis is more frequent in Level-II, III and distant metastasis is present predominantly in Supraclavicular Lymph nodes.

\section{Contribution by Authors}

(1) Dr. Siddharth, Resident Doctor has collected all the samples, examined and interpreted all the smears and slides and corresponded with Journal Editors.

(2) Dr. Dhaval as Senior Consultant and PG Guide, supervised and guided him in all steps and improved at his best.

What this study adds to existing Knowledge: We hope, this study will helpthe pathologists to know the incidence of various metastatic malignancies in cervical nodes\&clinicians to know the probable primary site origin in case of metastasis of unknown origin in cervical lymph nodes.

\author{
Abbreviations \\ AOM- Angle of Mouth \\ BM- Buccal Mucosa \\ BOT- Base of Tongue \\ FNAC- Fine Needle Aspiration Cytology \\ IHC- Immunohistochemistry \\ LN- Lymph Node \\ PNET- Primitive Neuroectodermal Tumor \\ RCC- Renal Cell Carcinoma \\ SCC-Squamous Cell Carcinoma
}

Funding: Nil; Conflict of Interest: None initiated Permission from IRB: Yes

\section{References}

1. Stanley P. L. Leong, Blake Cady, David M. Jablons, Julio Garcia-Aguilar, Douglas Reintgen, J. Jakub, S. Pendas, L. Duhaime, R. Cassell, M. Gardner, et al. Cancer Metastasis Rev. 2006 Jun; 25(2): 221-232. doi: 10. 1007/s10555-006-8502-8.

2. López F, Rodrigo JP, Silver CE, et al. Cervical lymph node metastases from remote primary tumor sites. Head Neck. 2016 Apr;38 Suppl1:E2374-85. doi: 10.1002/hed.24344. Epub 2015 Dec 29.
3. Blaszyk H, Hartmann A, Bjornsson J. Cancer of unknown primary: clinicopathologic correlations. APMIS. 2003 Dec;111(12):1089-94.

4. Dabbs D. Immunohistology of metastatic carcinoma of unknown primary in Diagnostic Immunohistochemistry. Churchill Livingstone, second edit.2006.

5. Jesse RH, Perez CA, Fletcher GH. Cervical lymph node metastasis: unknown primary cancer. Cancer. 1973 Apr;31(4):854-9.

6. Rai NN, Pratangia P, Meena SP. Role of fine needle aspiration cytology in diagnosis of metastatic lymphadenopathy. J. Evid. Based Med. Healtc. 2016; 3 (18), 738-741

7. Buckley JG, Feber T. Surgical treatment of cervical node metastases from squamous carcinoma of the upper aerodigestive tract: evaluation of the evidence for modifications of neck dissection. Head Neck. 2001 Oct; 23 (10):907-15.

8. Wagh A. Cervical Lymph Nodes: A Hotbed for Metastasis of Malignancy. Clin Oncol. 2018; 3: 1497.

9. Selvasekaran R, Cherian JV, Venkataraman J. Metastasis of hepatocellular carcinoma to Virchow's node: have the tumor cells gone astray? Hepatobiliary Pancreat Dis Int. 2007 Dec;6(6):650-2.

10. Bennett AK, Mills SE, Wick MR. Salivary-type neoplasms of the breast and lung. Semin Diagn Pathol. 2003 Nov;20(4):279-304.

11. Minna, JD.; Higgins, GA.; Glatstein, EJ. Cancer of the lung. In: DeVita, VT., Jr; Lawrence, TS.; Rosenberg, SA., editors. DeVita, Hellman, and Rosenberg's Cancer: principles \& practice of oncology. 10. Philadelphia, PA: Wolters Kluwer Health; 1982. p. 396-474.

12. Carlson ER, Reddi SP, Monteleone KL. Metastatic lung cancer of the neck: report of 2 cases. J Oral Maxillofac Surg. 2002 Sep;60(9):1057-61.

13. Davis RS, Flynn MB, Moore C. An unusual presentation of carcinoma of the lung: 26 patients with cervical node metastases. J Surg Oncol. 1977; 9 (5): 503-7.

14. Aldridge T, Kusanale A, Colbert S, Brennan PA. Supraclavicular metastases from distant primaries: what is the role of the head and neck surgeon? Br J Oral Maxillofac Surg. 2013; 51:288-293. 
15. El-Foll HA, El-Sebaey HI, El-Kased AF, Hendawy A, Kamel MM (2015) Pattern and Distribution of Lymph Node Metastases in Papillary Thyroid Cancer. J Clin Exp Pathol 5:204.

16. Schuller DE. Management of cervical metastasis in head and neck cancer. Washington, D.C.: American Academy of Otolaryngology, Head and Neck Surgery Foundation; 1982

17. Robbins KT, Clayman G, Levine PA, et al. Neck dissection classification update: revisions proposed by the American Head and Neck Society and the American Academy of Otolaryngology-Head and Neck Surgery. Arch Otolaryngol Head Neck Surg. 2002 Jul; 128 (7): 751-8.

\section{Original Research Article}

18. Lindberg R. Distribution of cervical lymph node metastases from squamous cell carcinoma of the upper respiratory and digestive tracts. Cancer. 1972 Jun;29(6): 1446-9.

19. Alberto Daniele Arosio, Lorenzo Pignataro, Renato Maria Gaini, Werner Garavello, Neck lymph node metastases from unknown primary.Cancer Treat Rev. 2016 Dec 10; 53: 1-9

20. Shukla P, Gupta D, Bisht SS, et al. Metastatic squamous cell carcinoma neck with occult primary: A retrospective analysis. Indian J Med Paediatr Oncol. 2009;30(4):124-30

\section{How to cite this article?}

Jetly D, Thummar S. Pattern of Metastasis in Cervical Lymph Nodes and Topographic Distribution of Primary Site: Study of 375 Cases. Trop J Path Micro 2019;5(3):137-143.doi:10.17511/jopm.2019.i03.05. 